commencement of the attack of illness for which medical advice was sought, he had been drinking spirits and porter freely at short intervals. On the 3rd of June he was remarked to be much depressed in spirits, and his manner created some alarm on the part of his family. The following night he spent with. out sleep; he was also very restless, and raved a good deal. The following morning, being requested by his family to visit him, I found him, at nine A.M., June 5th, talking incoherently, and sometimes attempting to get out of bed. He could, however, without much difficulty, be persuaded to lie down again. Countenance more flushed than natural; conjunctiva very vascular; pulse 90, full, and resisting; tongue furred; skin moist. Ordered, tincture of opium, a drachm; potassio-tartrate of antimony, two grains; water, eight ounces: mix. Two tablespoonfuls to be taken hourly until sleep is produced. Eleven P.M.: Has had no rest since my visit this morning; has not attempted to get out of bed, but still continues to talk incoherently; pulse 80, full. Had taken the entire of the mixture which was ordered this morning. Ordered: muriate of morphia, a grain; rectified spirit of wine, ten drops: mix, and add water, an ounce, for a draught to be taken immediately, and repeat every third hour if necessary.

June 6th.-Nine A.M.: Had taken four draughts; had slept during the night; delirium still continues; perspiration copious; pulse 80, resisting; countenance paler than usual. After some consultation with two of my medical friends, we determined on administering chloroform, and accordingly, about a drachm and a half being poured on a sponge, it was applied to the nostrils. Spasmodic respiration and violent plunging of the body were almost immediately produced; however, the sponge being firmly held to the nostrils, he was, after a few moments, in the anæesthetic condition. He remained to all appearances in a placid sleep for about eight minutes, and then awoke, yawned, and looked about him inquisitively. After a few moments, he talked a little incoherently. He continued in a restless state, however, raving but a little for about half an hour, and then fell into a quiet, deep sleep, and remained so for nearly fourteen hours, and awoke with clear and sound intellectual faculties. This case afterwards progressed favourably, and the man is now quite well, and engaged at his busi ness.

Having considered much on the inses of chloroform, and having gained much information on this subject from the perusal of the valuable periodical to which this report is sent it occurred to me that its effects in delirium tremens, when the remedies with which we are most familiar in the treatment of this disease have failed, might be judiciously tried. It was also mentioned to me by a professional friend, that he read a short time since in THE LA NCET, the history of a case of this nature, in which chloroform was used with beneficial results. I consider it to be useful to the profession and the public in general, to put on record a second case, showing, in some degree, the beneficial influence of this powerful agent

It is somewhat remarkable, that a decidedly good effect could have been produced in this case by the action of the chloroform, in consequence of the quickness with which the insensibility passed off, not continuing longer than eight minutes; but we are obliged to acknowledge its good effects when we compare the patient's state before the adininistration of the chloroform with his remarkably improved condition when he recovered from the insensibility, and although he even then raved, nevertheless he looked more intelligent, and reason appeared to be returning. On an immature consideration of this case, I am inclined to believe that the chloroform produced some peculiar state of the cerebrum favourable to the action of the sedatives previously taken, and that by virtue of their action, the sleep which terminated in recovery was produced.

Maryborough, Queen's County, Ireland, 1848 .

\section{ON THE \\ IMPORTANCE OF PHRENOLOGY IN MEDICAL DIAGNOSIS.}

By J. L. LEVISON, Esq., Brighton.

THE following phrenological cases will show the practical advantage of phrenology to the medical profession; and hence will not need any apology on my part for submitting them to the consideration of the readers of THE LANCET.

A short time since, two servants of a surgeon in this town came to me to have some fractured teeth removed. Afterwards, one of them said that her mistress particularly requested that I would look at her head, as she suffered very great pain at one particular part of it; that her master had cupped her, but without any permanent relief to her. I bade her take off her cap, and show me the place. She put her finger at the back of her head, on the organ of philoprogenitiveness. This organ was large, and her moral organization above mediocrity. The following interrogatories were then put to her:- "Do you feel pain at this present time?"- "Yes, Sir; it is a dull, heavy pain." "Have you had a child "" " Yes, Sir; and it died suddenly." "Are you a married woman?"-Yes, Sir." "Where is your husband ?"-" $\mathrm{He}$ is in London." "Are you separated from him; or is this a mere accidental circumstance ?" - "He is residing with a family" "When your baby died, did you fret and grieve much for it ?"-." I did, Sir." "And you think about it still ?"-" Yes, Sir; I am constantly thinking of it," \&c.

My advice was that she should endeavour to forget it-to feel the absurdity and the sinfulness of brooding over her loss; all fretting or discontent could not bring it back again. That she should cultivate a better state of mind, by submitting to the dispensations of Providence, \&c. If she did so, she would then soon lose the sense of weight and pain of which she complained. But if she did not, she would find the annoying pain almost intolerable; and that, if persisted in, it would ultimately upset her mind.

Is not this case one among numerous other instances which have been collected, as proving the immense power obtained by the aid of phrenology in relieving and preventing mental disturbance, $\rightarrow$ as the cause of the disturbed function was ascertained merely from my knowledge of the physiology of the brain ?

\section{Defective Organ of Colour.}

A short time since, the writer received a note from a medical gentleman of this town, requesting him to " examine the perceptive faculties of the bearer, and say if they had anything peculiar about them." The messenger was very taciturn as he did not answer me when I said, "I could not opine the object of such an examination." I then desired him to sit down, and passed my thumb across the eyebrows, \&c., giving particular attention to relative development of the perceptive faculties, my automatic visitor remaining quite passive. I then said-" All your perceptive faculties are very good, except the organ of colour, which is strikingly defective." A something more like animation seemed manifested by my unknown subject, as he said, "Will you write down these remarks ?" I did so. He then asked if I had any further observations to make on the defective power. "Yes; it is my opinion that you cannot distinguish one colour from another." After thanking me, he said, "It is due to you to tell you how and why I came to trouble you. I am a draper, living with my uncle, Mr. - but from the repeated disputes with our customers on colours, my friends considered that $I$ had some defect of sight, and they sent to Mr. - (who is a skilful oculist;) he examined my eyes, but could not discover any defect, and then he sent me to another gentleman, (the writer of the note mentioned above,) who said immediately, "It is not any defect of sight, but of brain !' And noticing my surprise at this statement, he added, ${ }^{6} I$ will give you a note to a gentleman, who will tell you in an instant what is the matter with you, without your saying anything to him.' And from what is stated above, it will be obvious that his estimation of the value of a practical knowledge of phrenology was not in. correct.

Brighton, Dec. 1848.

REPORT OF A

\section{CASE OF INTUS-SUSCEPTION IN A CHILD FOUR MONTHS OLD.}

BX H. F. CARTER, M.D., M.R.C.S., Shoreham.

On Friday, the 8 th of December last, $I$ was summoned to the female child of a Mr. D- in this town, whom I found suffering from very severe vomiting, and whose bowels had not been relieved for two days previously. I immediately instituted a careful examination of the abdomen, and could easily detect a large, sausage-like body in the left ilium there was no tenderness over the rest of the abdomen, and but slight tenderness over the tumour itself; the child did not appear particularly heated or feverish, and the lungs were acting freely, and with perfect ease; tongue clean and natural.

My first efforts were directed to remove the vomiting; and after applying several internal remedies, and a mustard cataplasm externally, I at length had recourse to the diluted blister-fluid, which vesicated immediately, and overcame the 
vomiting. I then rang the changes of sulphate of potass and rhubarb, castor oil, calomel, \&c., but could get nothing to produce the slightest effect. Enemata were carefully and plentifally applied; but they appeared to reach a certain point, and to be squirted out again with great violence.

The child continued to suffer excruciating agony from spasmodic pain, coming on at intervals, and gradually sunk lower, in spite of every contrivance that could be thought of. The tumour persisted to the last, and considerable tenderness supervened over its surface.

On the 12th of December my little patient died exhausted. I had concluded that freces, indurated and inspissated, had blocked up a portion of the large intestine.

On making a careful post-mortem examination, I found the origo mali to reside where I had anticipated; but the state of the parts was very different to what $I$. had supposed. On cutting into the tumour, I found that an obstruction to the passage of fres from above had been created by a displacement of the bowel, in which a portion of it had passed into itself, just as one portion of the finger of a glove might be pulled into the remaining part by the withdrawal of the hand. The contained portion of intestine I conceive to have been congenitally displaced; for it was so thickened and solid as to give the containing gut, before it was opened, an appearance and feeling as though it were filled with solid contents; a quantity of fat and flesh-like substance was deposited in the displaced portion, and altogether it had such a different aspect from the remainder of the intestine, as must have required considerable time to bring about; but I could easily show its continuity and original identity with the rest of the tube.

From its birth the child had suffered from disordered bowels and was liable to those feelings and inconveniences one would imagine the obstruction should give rise to. No doubt the fæces travelled by the side of the depending inverted gut, and it would appear, that as this increased in size, the passage gradually diminished, until at length, becoming obliterated, the child died from symptoms of invincible obstruction of the bowels.

I may mention that at one time I administered about four drops of Battley's solution, but it produced no effect whatever, and in nowise mitigated the pain, or abated the spasm.

I should be interested to learn the particulars of any similar case that may have occurred in the practice of any of your correspondents.

New Shoreham, 1849 .

\section{REPORT OF A CASE OF RUPTURE OF THE STRAIGHT SINUS.}

By F. G. W. MULLAR, M.D. Edin., \& M.R.C.S.E., Linlithgowshire.

JAMES A-, aged fifty-eight, (tailor,) of spare habit of body, and rather intemperate, felt himself, whilst at the communion table, on Sunday, Dec. 10, 1848, suddenly chilled, and after receiving the sacrament, contrived to reach his home, (at halfpast two P.M., ) not many yards distant from the church. When he got there his wife advised him to sit closer to the fire, which he did, but immediately after seating himself he said that he felt a severe pain in his head, and a sensation as of hot water being poured over it; he, directly after this, fainted. I was sent for, and found him in the following condition: the pulse scarcely perceptible; pupils slightly contracted; jaw drooping; countenance cadaverous and sunk; fæces and urine passing involuntarily, with severe retching; his body and extremities of a deathly coldness. I was also told by his friends that he had been, during the last week, very much grieved and annoyed with some family affairs; that he had been tipsy on the Saturday night, and that he had eaten little or nothing during the whole of Sunday. He seemed to be unconscious of all around him. (I was called to see him on a previous occasion, about two months ago, and found him in a state of syncope, from which he recovered by the usual remedies in a few moments; I also was told that that was the only time he ever had had a fit of any kind, and that he had never had much sickness.) In the present state, my first impression was, to bring on reaction, which was promoted by hot fomentations, and a large sinapism over the stomach, accompanied by dry friction over the other parts of the body. In about forty minutes reaction commenced; the vomiting and purging also abated. Now his breathing became every moment more stertorous; the pulse wasstill scarcely perceptible: I found the pupils contracted to the smallest possible point; the pulsations in the carotids became strong and bounding; but there seemed to be little or no return of blood from the head, as the external jugular veins were collapsed and empty. I bled him, and with difficulty obtained between twenty and twenty-five ounces of blood from his arm, and ordered eight leeches to be applied behind each ear. The hair was also removed, and cold water was constantly applied; the fomentations to be continued, and four or five ounces of mustard to be added to the hot water. After the bleeding and leeching the breathing became easier, and the right pupil dilated beyond the natural size, although the left remained as small as before; the pulsations of the carotids were less laboured. His bowels not having been moved since the. purging stopped, I deemed it proper to put two drops of croton oil upon his tongue, as he could not swallow, but this having procured no stool, I ordered the following enema, at eight P.M.: Castor oil, and oil of turpentine, of each an ounce; barleywater, a pint; mix: and to be repeated, if no evacuation, or if the symptoms did not improve. At nine P.M., the injection having been retained and no evacuation procured, it was repeated, but with little better effect. At ten P.M., I put two drops of croton oil upon his tongue, but procured no stool. The pulsations of the carotids becoming stronger, and the breathing more stertorous, I, at eleven P.M., attempted to bleed from the external jugular vein, but only succeeded in getting. one or two drops of blood; after this he gradually sunk, and at two, A.M. he expired.

Post-mortem examination, thirty-six hours afterwards. - I opened the head, and found, upon removing the calvarium, the dura mater very tense, and communicating a feeling to the fingers, as if it were filled with fluid; it was of a much darker colour than usual. I next proceeded cautiously to make an incision into the dura mater, on a line with the edge of the skull, of the right side, when a great quantity of dark venous blood (five or six ounces) made its escape. The brain was scarcely perceptible, the - vessels of the pia mater being so congested that they entirely obscured the view of that organ; I conld compare it to nothing better than a newly removed placenta.

I then proceeded to look for the source of hæmorrhage, and at last found that the straight or fourth sinus had been ruptured near its juncture with the torcular Herophili; the rent was nearly one-eighth of an inch long, and extended partly in to the torcular Herophili.

The vessel was very much constricted in front of the laceration, by bands of lymph; so much so, that I could not get a full-sized probe passed, and I also found the torcular Herophili distended or dilated to a larger-size than a pigeon's egg. The ventricles were filled with coagulated blood, and much distended, the substance of the brain was very much injected, being of a reddish-brown colour, and much softened. I am sorry that time would not permit me to examine the contents of the chest and abdomen, but from what I saw I considered the vessels generally to have been healthy, not being able to detect any ossific deposits.

Bathgate; Linlithgowshire, 1849.

\section{EXTENSTVE FRACTURE OF THE SKULL.} DISLOCATION OF THE FEMUR.

\section{By RICHARD HODGES, Ase, Surgeon, Rochford, Essex.}

CASE 1.-John T-, sixty-five years of age, on the 31st of March, 1847, received a severe blow on the right side of the head, above the ear, from the iron ent of a hoe. (The young man who inflicted the injury was tried at the Chelmsford assizes, found guilty, and sentenced to death.) The concussion of brain necessarily the result of the application of such violence was recovered from before I saw him. He had been once or twice sick; and there had been bleeding to some extent from the nose and right ear.

Upon examination, the upper part of the right eat was found cut out, and there was considerable swelling of the side of the head immediately above it; there were also a couple of wounds on the right side of the forehead, produced by the fall. (The ear was mutilated by the instrument at the time the blow was given.) He was perfectly conscious-I am speaking of a period of two hours from the accident-had little or no headach; the pupils were natural, and obedient to the stimulus of light.

From this period he went on apparently well, the swellings on the side of the head and forehead gradually subsided, and the wounds healed. At no subsequent time had he any pain in the head, the appetite was good, and he slept well: impairment of the sight of the right eye was the only inconvenience present.

In three or four days after the accident he dressed him. 